\title{
MINAT KEPEMILIKAN KARTU KREDIT (STUDI KASUS KOTA BOGOR)
}

\author{
Bunga Ayu Lestari ${ }^{*}$, , Budi Suharjo ${ }^{* *}$, dan Istiqlaliyah Muflikhati**) \\ *) Sekolah Bisnis, Institut Pertanian Bogor \\ Jl. Raya Pajajaran, Bogor 16151 \\ ${ }^{* *}$ Departemen Matematika, Fakultas Matematika dan Ilmu Pengetahuan Alam, Institut Pertanian Bogor \\ Jl. Meranti Wing 22 level 4-5, Kampus IPB Darmaga Bogor 16680 \\ **) Departemen Ilmu Keluarga dan Konsumen, Fakultas Ekologi Manusia, Institut Pertanian Bogor \\ Gedung GMSK Lantai 2, Kampus IPB Dramaga Bogor 16680
}

\begin{abstract}
The growth of the credit card ownership in 2014 is not suitable with the projection of Bank Indonesia (BI). This issue influences the program of the government regarding cash leash society and the effectiveness of BI's regulation on credit card. It is not clear whether the growth is from the new credit card owners or the existing owners. This is possible because the marketers often offer the credit card to existing owners who have already credit cards. The objective of the research is to analyze the factors of the people's interest in possessing a credit card in Bogor. The analysis used is Planned Behavior Theory, statistical analysis and structural equation modeling (SEM). The result shows that only $17 \%$ of the people are interested in owning a credit card. Based on the statistical analysis using SEM shows that behavior, norm, and controlling behavior are significant and positive to the owning of the credit card. The behavior control through indicators presented fewer people using credit card in the environment of consumer is a determinant factor in influencing the interest on ownership of the credit card.
\end{abstract}

Keywords: theory planned behavior (TPB), consumer behavior, SEM credit card

\begin{abstract}
ABSTRAK
Pertumbuhan kepemilikan kartu kredit sepanjang tahun 2014 tidak sesuai dengan proyeksi Bank Indonesia (BI). Hal ini tentunya berdampak pada program pemerintah mengenai cash lessh society dan keefektifan peraturan BI terkait kartu kredit. Selain itu, belum diketahui juga secara pasti pertumbuhan tersebut datang dari pemilik baru atau justru pengguna eksisting. Hal ini dimungkinkan karena pihak marketing umumnya memasarkan kartu kredit pada nasabah yang sebelumnya telah memiliki kartu kredit. Tujuan dari penelitian ini adalah menganalisis faktor-faktor yang menentukan minat seseorang dalam memiliki kartu kredit dengan mengambil studi kasus kota Bogor. Analisis yang digunakan dalam penelitian ini adalah Model Teori Planned Behavior (TPB), analisis statistik, dan structural equation modeling (SEM). Hasil penelitian penunjukkan minat kepemilikan kartu kredit hanya sebesar 17\%. Berdasarkan analisis statistik dengan SEM menunjukkan bahwa sikap, norma dan kontrol perilaku memiliki hasil signifikan dan positif terhadap minat. Kontrol terhadap perilaku melalui indikator sedikitnya orang yang menggunakan kartu kredit di lingkungan sekitar konsumen, menjadi faktor determinan yang dapat memengaruhi niat kepemilikan kartu kredit.
\end{abstract}

Kata kunci: theory planned behavior (TPB), kontrol perilaku, SEM, kartu kredit

\footnotetext{
${ }^{1}$ Alamat Korespondensi:

Email: bunga.al87@gmail.com
} 


\section{PENDAHULUAN}

Dalam rangka mendorong masyarakat agar menggunakan instrumen non tunai (Cash Less Society/CLS), pemerintah melalui BI secara resmi mencanangkan gerakan nasional non tunai (GNNT). Berbagai instansi pemerintah lainnya spserti Otoritas Jasa Keuangan (OJK), Kementerian Ketenagakerjaan (Kemenaker), serta Badan Nasional Penempatan dan Perlindungan Tenaga Kerja Indonesia (BNP2TKI), juga turut mendukung tumbuhnya CLS dengan melakukan penandatanganan nota kesepahaman yang berisikan peningkatan kepemilikan transaksi non-tunai dan perluasan akses keuangan bagi tenaga kerja indonesia di Jakarta.

Kartu Kredit merupakan salah satu alat pembayaran dengan menggunakan kartu (APMK). Kartu kredit menawarkan dua fungsi yang berbeda kepada konsumen yaitu sebagai alat pembayaran dan sumber kredit (Canner dan Luckett (1992) dalam Abdelrahmamn, 2011). Peran kartu kredit sebagai salah satu indikator tumbuhnya CLS, merupakan sistem pembayaran yang aman dan praktis. Jika kartu kredit digunakan secara bijak maka kartu kredit akan memberikan manfaat. Ketika kartu kredit digunakan dengan cara yang salah maka kartu kredit akan mengakibatkan berbagai masalah finansial bagi penggunanya (Gunawan dan Linawati, 2013).

Kepemilikan kartu kredit di negara-negara maju, begitu luas dikalangan masyarakat dengan tingkat penetrasi mendekati nilai 100\% (Abdul-Muhmin dan Umar, 2007), sedangkan di Indonesia masih terbilang rendah. Melalui data yang dipublikasi oleh BI (Gambar 1), perkembangan jumlah kartu kredit beredar di Indonesia sendiri pada tahun 2014 mencapai 16 juta pemilik. Namun, hal tersebut masih jauh dari target yang diharapkan, karena BI sendiri telah memproyeksikan kepemilikan kartu kredit tumbuh hingga mencapai 20 $25 \%$ pada tahun 2014 atau sebesar 30,01 juta-37,52 juta.

Biro Riset Infobank (birI) menyebutkan bahwa aturan yang memperketat kepemilikan kartu kredit dari BI yang tertuang dalam Peraturan BI (PBI) Nomor 14/2/PBI/2012 dan ketentuan teknis kepemilikan kartu kredit melalui Surat Edaran BI (SE BI) Nomor 14/27/DASP/2012 pada September 2012, telah menjadi penghambat pertumbuhan kepemilikan kartu kredit tersebut (IBI, 2009). Dugaan lain rendahnya pertumbuhan kepemilikan kartu kredit juga dapat disebabkan oleh semakin tingginya kesadaran orang untuk tidak menggunakan kartu kredit. Sulistyawaty (2012) menemukan bahwa faktor tidak butuh memengaruhi atau memotivasi perilaku konsumen untuk tidak memiliki kartu kredit. Penelitian Fathia (2012) menyampaikan bahwa terdapat perilaku masyarakat yang menolak menggunakan kartu kredit, dengan masalah keamanan menjadi faktor penyebab utama. Dalam penelitian Sayono (2009) menyebutkan alasan utama seseorang tidak memiliki kartu kredit adalah ketakutan berhutang.

Kondisi aktual lapang menunjukkan bahwa penawaran kartu kredit ditunjukkan kepada konsumen yang telah memiliki kartu kredit. Bagi bank penerbit kartu kredit, terutama yang telah memiliki nama besar atau berstatus badan usaha milik negara (BUMN), catatan rekam jejak dalam berhutang dinilai penting untuk dimiliki seseorang yang akan mengajukan kepemilikan kartu kredit. Pengajuan kepemilikan kartu kredit baru seringkali dispersyaratkan untuk memiliki kartu kredit sebelumnya sehingga bagi konsumen yang melakukan pengajuan pertama atau belum memiliki kartu kredit selalu menghadapi penolakan.

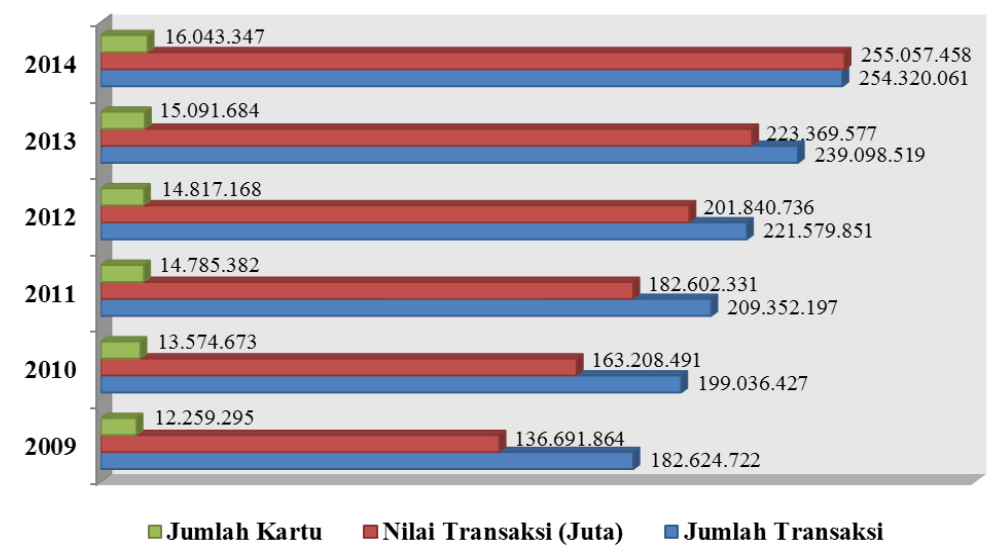

Gambar 1. Grafik pertumbuhan kartu kredit (Bank Indonesia, 2015) 
Keberadaan kartu kredit diketahui dengan baik oleh masyarakat. Untuk sebagian kalangan, kartu kredit bahkan mendukung gaya hidupnya dan dimanfaatkan pada hampir semua transaksi pembelian barang atau jasa (Sulistyawaty, 2012). Akan tetapi, masih banyak konsumen yang belum menggunakan kartu kredit, bahkan menolak untuk memiliki kartu tersebut.

Penelitian ini membahas faktor-faktor yang Memengaruhi seseorang dalam minat kepemilikan kartu kredit. Pemasar atau pihak bank perlu mempelajari alasan apa yang melatar belakangi seseorang dalam mengambil keputusan untuk memiliki kartu kredit. Teori Perilaku Terencana (Theory Planned Behaviour/ TPB) adalah model sikap yang memperkirakan minat atau niat konsumen untuk melakukan suatu perilaku atau tindakan (Sumarwan, 2011). Niat tidak hanya bergantung kepada sikap, tetapi juga norma-norma subjektif atau tekanan sosial yang dilakukan oleh orang lain, seperti orang tua dan teman, untuk melakukan atau tidak melakukan suatu perilaku (Haryono, 2013).

Theory Planned Behaviour (TPB) dalam penelitan Matheison (1991), yang dikutip oleh Rochmawati (2013), terbukti mampu menyediakan informasi yang lebih spesifik mengenai perilaku individu dibandingkan teori yang lain. Hasil penelitian Park et al. (2012) bahkan menunjukkan bahwa TPB dapat menjelaskan mengenai intention (minat) dengan cukup baik. Dalam penelitian Rochmawati (2013) mengenai pengaruh sikap, norma subjektif, kontrol perilaku persepsian, persepsi risiko, persepsi kebermanfaatan terhadap niat penggunaan kartu kredit, menunjukkan bahwa niat seseorang ditentukan oleh norma subjektif (subjective norm), persepsi risiko (perceived risk), dan persepsi kebermanfaatan (perceived benefit).

Tujuan dari penelitian ini adalah mengidentifikasi minat masyarakat terhadap kartu kredit, menganalisis faktor-faktor yang memengaruhi masyarakat agar bersedia memiliki kartu kredit, dan memberikan alternatif rekomendasi strategi yang dapat digunakan untuk memengaruhi masyarakat dalam memiliki kartu kredit.

\section{METODE PENELITIAN}

Pengambilan sampel dilakukan secara non-probability sampling dengan metode convenience sampling. Pada prosedur convenience Sampling, sampel diambil berdasarkan kemudahan untuk mendapatkan sampel tersebut. Syarat responden yang digunakan pada penelitian ini adalah warga Kota Bogor yang berusia minimal 21 tahun, memiliki pendapatan diatas Rp3 juta per-bulan dan tidak memiliki kartu kredit. Total keseluruhan responden yang digunakan sebagai sampel berjumlah 86 responden

Dalam upaya menjawab tujuan penelitian, dilakukan sebuah studi kasus di Kota Bogor, dengan menggunakan data primer dan data pendukung. Data primer diperoleh dari tanggapan responden melalui wawancara langsung berdasarkan daftar pertanyaan. Responden memberikan informasi mengenai karakteristik konsumen di Bogor dan perilaku konsumen terkait kartu kedit. Terdapat sejumlah publikasi ilmiah, artikel-artikel melalui internet dan perpustakaan sebagai data pendukung.

Penelitian ini dibangun dengan mengacu kepada teori perilaku terencana atau TPB yang dikembangkan oleh Ajzen. Kemudian dilakukan penelitian terhadap perilaku responden dan minat responden terkait kartu kredit. Selanjutnya, menganalisis faktor-faktor yang memengaruhi minat masyarakat dalam kepemilikan kartu kredit, diantaranya adalah sikap terhadap perilaku yang terdiri atas keyakinan perilaku dan evaluasi konsekuensi, norma subjetif yang terdiri atas keyakinan normatif dan motivasi memenuhi, dan persepsi kontrol perilaku yang terdiri atas keyakinan kontrol dan kekuatan faktor kontrol. Kerangka penelitian seperti ditunjukkan pada Gambar 2.

Dalam TPB, perilaku aktual seseorang dalam melakukan suatu tindakan tertentu secara langsung dipengaruhi oleh niat perilakunya, yang secara bersama-sama ditentukan pula oleh sikap (attitude), norma subjektif (subjective norm), dan persepsi kontrol perilaku (perceived behavioral control). Fishbein dan Ajzen (1991) menjabarkan sikap terhadap perilaku didefinisikan sebagai perasaan individu positif atau negatif tentang melakukan suatu perilaku. Sikap positif berarti sikap yang memandang kartu kredit sebagai memberi ciri orang modern, mempermudah transaksi pembelian dan menaikkan harga diri (prestige) pemiliknya sedangkan sikap negatif berarti sikap yang memandang kartu kredit sebagai suatu pemborosan dan menyebabkan individu menjadi lebih konsumtif serta suka berhutang Rita dan Kusumawati (2011). Hal ini ditentukan melalui penilaian dari keyakinan seseorang mengenai konsekuensi yang timbul dari perilaku dan evaluasi dari keinginan konsekuensi-konsekuensi. Sikap terhadap 
perilaku (attitude toward behavior) dibentuk oleh behavioral belief (keyakinan perilaku), yaitu keyakinan bahwa perilaku akan menghasilkan suatu keluaran atau keyakinan terhadap adanya konsekuensi karena melakukan perilaku tertentu. Sikap terhadap perilaku juga dibentuk oleh outcomes evaluation/evaluation of the consequency (evaluasi konsekuensi), yaitu evaluasi seseorang terhadap keluaran atau evaluasi terhadap konsekuensi dari keyakinan perilaku.

Norma subyektif sebagai persepsi individu tentang apakah orang penting bagi individu berpikir perilaku harus dilakukan. Kontribusi pendapat dari setiap rujukan yang diberikan dibobot dengan motivasi bahwa seorang individu harus mematuhi keinginan rujukan itu. Bernthal (1999) menyampaikan bahwa norma pada pengguna kartu kredit, adalah sejauh mana konsumen percaya bahwa konsumen lain menggunakan kartu kredit memberikan efek pada keyakinan subjektif mereka. Norma subjektif (subjective norms) dibentuk oleh Normative Belief (keyakinan normatif), yaitu keyakinan terhadap orang lain (kelompok acuan atau referensi) bahwa mereka berpikir subjek seharusnya atau tidak melakukan suatu perilaku atau keyakinan normatif tentang harapan orang lain (kelompok acuan) terhadap dirinya mengenai apa yang seharusnya dilakukan. Selanjutnya, Norma subjektif (subjective norms) dibentuk oleh Motivation to comply (motivasi mematuhi), yaitu motivasi yang sejalan dengan keyakinan normatif atau motivasi yang sejalan dengan orang yang menjadi kelompok acuan. perilaku. Preceived behavioral control memandang pengendalian/kontrol yang dimiliki seseorang terhadap perilakunya berada pada sebuah kontinum dari perilaku yang mudah dilakukan dengan usaha dan sumber daya yang cukup. Behavioral control dibentuk oleh control belief (keyakinan pengendalian), yaitu probabilitas bahwa beberapa faktor menunjang suatu tindakan/ perilaku. Di samping itu, dibentuk oleh power of control factor/access to the control factor (kekuatan faktor pengendalian), yaitu akses subjek atau kekuatan subjek terkait faktor-faktor yang menunjang perilaku tersebut.

Analisis data dilakukan dengan menggunakan metode Structural Equation Model (SEM). Adanya analisis SEM memungkinkan untuk menguji model statistik yang biasanya dalam bentuk model - model sebab akibat (Hasan, 2012). Analisis SEM dapat memberikan analisis yang berbasis pada Confirmatory Factor Analysis (CFA) suatu model yang menggabungkan analisis korelasi, analisis regresi, analisis lintas, dan analisis faktor (Suharjo, 2002). Analisis data SEM diolah dengan bantuan software Lisrel 8.70. Lisrel merupakan suatu analisis peubah ganda yang digunakan untuk mendeskripsikan keterkaitan hubungan linier secara simultan peubah-peubah indikator, baik peubah eksogen maupun peubah indikator endogen sekaligus melibatkan peubah-peubah latennya (Suharjo dan Suwarno, 2002). Bentuk-bentuk umum model LISREL (general/full lisrel model) menurut Wijanto (2008) dapat dilihat melalui penjelasan berikut:

- Struktural Model $\eta=\mathrm{B} \eta+\Gamma \xi+\zeta$ perilaku didefinisikan sebagai persepsi seseorang terhadap hambatan dalam melakukan suatu

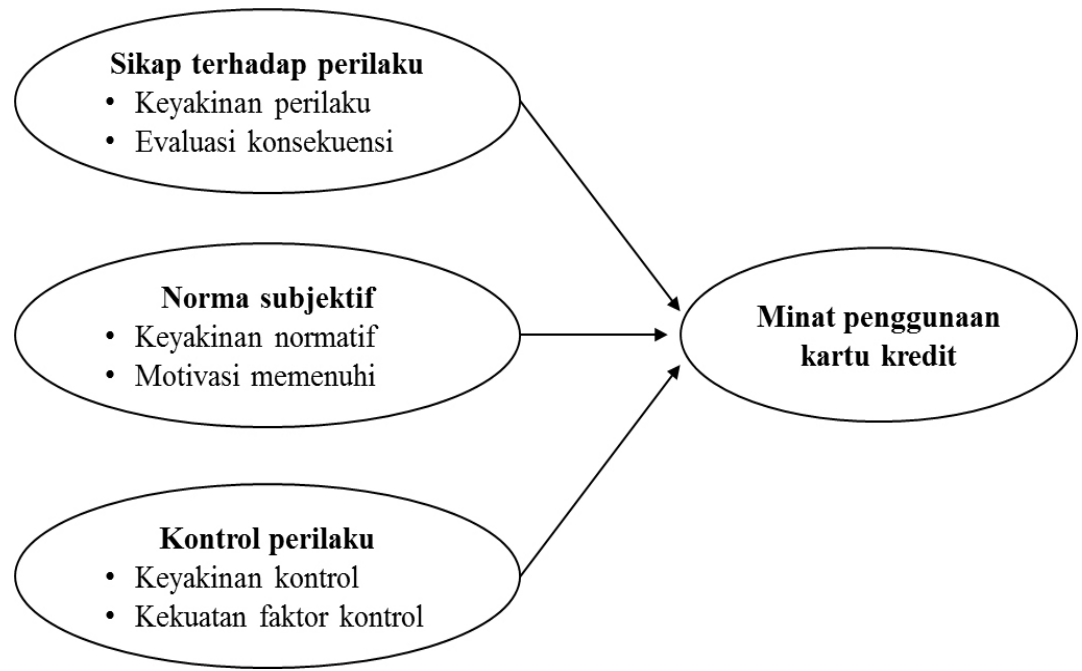

Gambar 2. Kerangka pemikiran penelitian 


\section{- Measurement Model}

Model Pengukuran untuk $Y$

$\mathrm{Y}=\Lambda \mathrm{y} \eta+\varepsilon$

Model Pengukuran untuk X

$\mathrm{X}=\Lambda \mathrm{x} \xi+\delta$

- Asumsi:

1. $\zeta$ tidak berkorelasi dengan $\xi$

2. $\varepsilon$ tidak berkorelasi dengan $\eta$

3. $\delta$ tidak berkorelasi dengan $\xi$

4. $\zeta, \varepsilon$ dan $\delta$ tidak saling berkorelasi (mutually uncorrelatted)

\section{5. $\Gamma-\mathrm{B}$ adalah non singular}

Variabel penelitian dikembangkan berdasarkan kajian literatur, wawancara terhadap beberapa pakar Kartu Kredit dan sebagian konsumen. Variabel eksogen dan variabel endogen diukur dengan skala Likert, yang diberi bobot nilai skala $1=$ Sangat Tidak Setuju (STS), skala 2 = Tidak Setuju (TS), skala $3=$ Antara Setuju dan Tidak (AST), skala $4=$ Setuju (S) dan skala $5=$ Sangat Setuju (SS). Variabel tersebut dapat terlihat melalui Tabel 1.

Tabel 1. Operasionalisasi variabel

Variabel Laten $\quad$ Variabel Indikator

\section{Eksogen}

Keyakinan $\quad$ 1) Saya mengetahui kartu kredit sebagai alat pembayaran non tunai

perilaku 2) Penggunaan kartu kredit sangat mudah dan praktis menurut saya

3) Kartu kredit memberikan seseorang cadangan dana saat darurat

4) Kepemilikan kartu kredit dapat menaikkan status sosial seseorang

5) Menggunakan kartu kredit dinilai lebih aman dibandingkan menggunakan uang tunai

6) Banyak keuntungan diskon yang ditawarkan dari kartu kredit yang tidak dirasakan oleh pengguna kartu debet atau uang tunai

7) Terdapat berbagai beban biaya dari kepemilikan kartu kredit, seperti bunga, annual fee dan biaya admin.

8) Kartu kredit dapat membantu kondisi keuangan seseorang karena dapat dibayarkan lain waktu secara sekaligus bahkan mengangsur

Evaluasi 9) Kartu kredit akan mempermudah transaksi keuangan seseorang

konsekuensi 10) Kemudahan penggunaan kartu kredit dapat membuat seseorang lebih konsumtif

11) Kartu kredit membuat seseorang merasa lebih aman untuk menghadapi kondisi kebutuhan keuangan yang mendesak

12) Memiliki kartu kredit dapat membuat bangga karena tidak semua orang dapat memperoleh kartu tersebut

13) Kartu kredit dapat membuat seseorang lebih nyaman dan efisien dalam melakukan suatu transaksi

14) Berbagai keuntungan yang ditawarkan kartu kredit dapat menghemat pengeluaran seseorang, seperti terdapat potongan harga

15) Merupakan nilai pengeluaran yang wajar, jika terdapat beban biaya dalam penggunaan fasilitas kartu kredit

16) Jika tagihan kartu kredit tidak terkendali, seseorang dapat berisiko terbelit oleh hutang atau gagal bayar

Keyakinan normatif

17) Keluarga menganjurkan saya untuk lebih baik memiliki kartu kredit

18) Rekan menganjurkan saya untuk lebih baik memiliki kartu kredit

19) Lingkungan sosial mendorong/memaksa menganjurkan saya untuk lebih baik memiliki kartu kredit

Motivasi mematuhi

20) Saya ingin melakukan apa yang dianjurkan keluarga saya untuk memiliki kartu kredit

Keyakinan kontrol

21) Saya ingin melakukan apa yang dianjurkan rekan saya untuk memiliki kartu kredit

22) Saya ingin melakukan apa yang, menjadi tuntutan lingkungan sosial saya untuk memiliki kartu kredit

23) Penggunaan kartu kredit dapat menunjang aktivitas seseorang yang selalu melakukan transaksi pembelian di berbagai tempat

24) Kartu kredit dapat membantu keuangan seseorang yang selalu membutuhkan dana lebih

25) Citra baik pada bank penerbit kartu kredit membuat saya mau memiliki kartu kredit.

26) Kemudahan persyaratan memperoleh kartu kredit mempermudah saya untuk memiliki kartu kredit

27) Saya mau memiliki kartu kredit jika banyak orang sekitar saya yang memiliki kartu tersebut

Kekuatan

28) Apabila saya jarang melakukan transaksi pembelian maka saya enggan memiliki kartu kredit

faktor kontrol

29) Kondisi keuangan saya yang cukup baik akan membuat saya enggan memiliki kartu kredit

30) Citra yang buruk dari bank penerbit kartu kredit akan membuat saya enggan memiliki kartu kredit

31) Apabila proses memperoleh kartu kredit cukup rumit maka saya akan enggan memiliki kartu kredit

32) Jika terdapat sedikit orang sekitar saya yang memiliki kartu kredit maka saya akan enggan untuk memiliki kartu tersebut

\section{Endogen}




\section{HASIL}

\section{Karakteristik Responden}

Karakteristik responden berdasarkan jenis kelamin, usia, status pernikahan, jumlah anggota keluarga, tingkat pendidikan, pekerjaan, dan rata-rata pendapatan per-bulan, terlihat pada Tabel 2. Terlihat bahwa sebagian besar responden berjenis kelamin pria (56\%) yang tidak memiliki kartu kredit. Hal ini diungkapkan dalam penelitian yang dilakukan oleh Themba dan Tumedi (2012) dan Safakli (2007) bahwa wanita lebih dimungkinkan memiliki kartu kredit dibandingkan pria. Lalu dari segi usia, responden terbanyak adalah berusia 21-35 tahun (80\%), yang merupakan tahap usia awal produktif. Komposisi yang berimbang antara yang berstatus menikah (50\%) dan belum menikah (50\%). Hal ini tentunya tidak sejalan dengan penelitian yang dilakukan Ramayah et al. (2002), Wickramasinghe dan Gurugamage (2009) dan Abdul-Muhmin dan Umar (2007) bahwa status pernikahan Memengaruhi kepemilikan kartu kredit. Berdasarkan tingkat pendidikan, sebagian besar adalah lulus S1(83\%), pekerjaan pegawai negeri sipil (41\%) dan memiliki pendapatan per bulan dengan kisaran Rp3.000.000Rp5.000.000 (59\%).

\section{Minat Responden Terhadap Kartu Kredit}

Survei menunjukkan bahwa mayoritas responden menjawab tidak berminat pada kartu kredit (48\%). Sedangkan 35\% diantaranya menjawab antara tertarik dantidak. Hanya sebesar $17 \%$ yangmenyatakan berminat terhadap kartu kredit. Alasan responden yang berminat dan tidak berminat terhadap kartu kredit disajikan pada Tabel 3. Bagi responden yang menyatakan tidak berminat terhadap kartu kredit beralasan karena tidak suka berhutang (22,1\%). Responden yang menyatakan berminat terhadap kartu kredit beralasan karena lebih fleksibel dan berminat pada fasilitas yang ditawarkan $(10,5 \%)$.

\section{Faktor-faktor yang Memengaruhi Minat Kepemilikan Kartu Kredit}

Melalui hasil analisis statistik SEM yang menguji pengaruh antar variabel diketahui bahwa variabel sikap terhadap perilaku (attitude toward behavior/ATB), variabel norma subyektif (subjective norms/SN) dan variabel persepsi kontrol perilaku (perceived behavioral control/PBC) memiliki pengaruh terhadap minat kepemilikan kartu kredit, dijelaskan pada Gambar 3.

Berdasarkan variabel-variabel yang diuji, menunjukan bahwa variabel PBC memiliki nilai faktor muatan yang paling besar 0,58 yang artinya kontrol perilaku memberikan pengaruhterbesardalamminatkepemilikan kartu kredit dibandingkan variabel lainnnya. Faktor lainnya yang memberikan pengaruh positif terhadap kepemilikan kartu kredit adalah SN $(0,48)$ dan ATB $(0,38)$ yang memberikan pengaruh paling kecil dalam minat kepemilikan kartu kredit.

Tabel 2. Karakteristik responden

\begin{tabular}{|c|c|c|}
\hline Deskriptif & Frekuensi & $\%$ \\
\hline \multicolumn{3}{|l|}{ Jenis kelamin } \\
\hline Pria & 48 & 56 \\
\hline Wanita & 38 & 44 \\
\hline \multicolumn{3}{|l|}{ Usia } \\
\hline $21-35$ & 69 & 80 \\
\hline $36-45$ & 11 & 13 \\
\hline $46-60$ & 6 & 7 \\
\hline \multicolumn{3}{|l|}{ Status pernikahan } \\
\hline Belum menikah & 43 & 50 \\
\hline Menikah & 43 & 50 \\
\hline \multicolumn{3}{|l|}{ Jumlah anggota keluarga } \\
\hline $1-2$ orang & 3 & 3 \\
\hline $3-4$ orang & 53 & 62 \\
\hline$>5$ orang & 30 & 35 \\
\hline \multicolumn{3}{|l|}{ Tingkat pendidikan } \\
\hline Lulus SMA & 5 & 6 \\
\hline Lulus Akademi (D1/D2/D3) & 1 & 1 \\
\hline Lulus S1 & 71 & 83 \\
\hline Lulus S2/S3 & 9 & 10 \\
\hline \multicolumn{3}{|l|}{ Pekerjaan } \\
\hline Wiraswasta/Pengusaha & 17 & 20 \\
\hline Pegawai Negeri Sipil & 35 & 41 \\
\hline Pegawai Swasta & 31 & 36 \\
\hline Pegawai BUMN & 1 & 1 \\
\hline Lainnya & 2 & 2 \\
\hline \multicolumn{3}{|c|}{ Rata-rata pendapatan per bulan } \\
\hline Rp3.000.000 - Rp5.000.000 & 51 & 59 \\
\hline Rp5.000.001 - Rp10.000.000 & 27 & 31 \\
\hline$>$ Rp10.000.000 & 8 & 9 \\
\hline
\end{tabular}


Tabel 3. Hasil tabulasi silang antara sebaran kepemilikan kartu kredit dengan minat responden

\begin{tabular}{ccccc}
\hline \multirow{2}{*}{ Kepemilikan KK } & \multicolumn{3}{c}{ Tingkat minat } & \multirow{2}{*}{ Total } \\
\cline { 2 - 4 } & Berminat & Antara berminat dan tidak & Tidak berminat & 86 \\
Tidak & 15 & 30 & 41 & $100 \%$ \\
$\%$ & $17,4 \%$ & $34,9 \%$ & $47,7 \%$ & 34 \\
Ya & 17 & 10 & 7 & $100 \%$ \\
$\%$ & $50 \%$ & $29,4 \%$ & $20,6 \%$ & $100 \%$ \\
\hline
\end{tabular}

Untuk menganalisis faktor-faktor yang memengaruhi minat (intention) kepemilikan kartu kredit pada responden, dilakukan pengujian terhadap hipotesis. Pengujian hipotesis untuk menguji pengaruh langsung ATB, SN dan PBC terhadap minat (intention) kepemilikan kartu kredit dapat dijelaskan pada Tabel 4.

Tabel 4. Uji hipotesis

\begin{tabular}{lccc}
\hline \multicolumn{1}{c}{ Hipotesis } & Koefisien & T-hitung & Keterangan \\
\hline $\mathrm{H} 1: \mathrm{ATB} \rightarrow$ Minat & 0,38 & 3,96 & Significant \\
$\mathrm{H} 2: \mathrm{SN} \rightarrow$ Minat & 0,48 & 4,93 & Significant \\
$\mathrm{H} 3: \mathrm{PBC} \rightarrow$ Minat & 0,58 & 6,50 & Significant \\
\hline
\end{tabular}

H1: Sikap terhadap perilaku (ATB) berpengaruh terhadap minat kepemilikan kartu kredit

Pada hipotesis 1 menyatakan bahwa sikap terhadap perilaku(ATB) berpengaruh terhadap minat kepemilikan kartu kredit. Hasil nilai t-hitung adalah sebesar 3,96 atau $>1$,96. Artinya, H1 diterima, sikap terhadap perilaku berpengaruh terhadap minat kepemilikan kartu kredit. Dengan demikian minat kepemilikan kartu kredit dilandasi oleh kepercayaan responden terhadap kartu kredit itu sendiri. Hal ini sejalan dengan penelitian yang dilakukan oleh Dewi (2015) bahwa minat seseorang menggunakan kartu kredit ditentukan oleh sikap (attitude).

H2: Norma subjektif (SN) berpengaruh terhadap minat kepemilikan kartu kredit

Pada Hipotesis 2 menyatakan bahwa norma subjektif (SN) berpengaruh terhadap minat kepemilikan kartu kredit. Hasil nilai t-hitung adalah sebesar 4,93 atau > 1,96. Artinya, $\mathrm{H} 2$ diterima, norma subjektif berpengaruh terhadap minat kepemilikan kartu kredit. Dengan demikian minat kepemilikan kartu kredit dipengaruhi faktor-faktor yang ada di luar dirinya. Hal ini tidak sejalan dengan penelitian yang dilakukan oleh Rita dan Kusumawati (2011) bahwa norma subjektif tidak Memengaruhi sikap menggunakan kartu kredit.
H3: Persepsi kontrol perilaku (PBC) berpengaruh terhadap minat kepemilikan kartu kredit

Pada Hipotesis 3 menyatakan bahwa persepsi kontrol perilaku(PBC) berpengaruh terhadap minatkepemilikan kartu kredit. Hasil nilai t-hitung adalah sebesar 6,50 atau $>1,96$. Artinya, H3 diterima, persepsi kontrol perilaku berpengaruh terhadap minat kepemilikan kartu kredit.

\section{Implikasi Manjerial}

Citra negatif kartu kredit yang membuat seseorang selalu berhutang dan risiko berurusan dengan debt collector, hendaknya dapat diantisipasi dengan baik. Perbankan dan pemerintah dapat melakukan kampanye positif mengenai penggunaan kartu kredit yang terkontrol dan sesuai dengan fungsinya untuk menghindari penyalahgunaan. Dalam hal ini, lembaga terkait hendaknya dapat secara aktif turut serta mengedukasi penggunanya.

Besarnya biaya dari penggunaan kartu kredit, seperti bunga, denda, dan admin, agar dievaluasi dengan baik oleh perbankan. Hendaknya perbankan dapat menetapkan bunga kredit yang rendah dan biaya penggunaan kartu kredit yang tidak terlalu mahal bagi konsumen. Biaya-biaya yang dikenakan harus disesuaikan kemampuan konsumen sehingga tidak merasa terbebani.

Risiko keamanan menggunakan kartu kredit perlu diperhatikan dengan baik. Perbankan hendaknya dapat meningkat pengawasan dalam keamanan penggunaan kartu kredit sehingga meminimalisir kasus pembobolan kartu kredit yang terjadi dan konsumen dapat merasa nyaman bertransaksi dengan menggunakan kartu tersebut. 


\section{KESIMPULAN DAN SARAN}

\section{Kesimpulan}

Hasil penelitian ini dapat disimpulkan bahwa, minat responden terhadap kepemilikan kartu kredit masih sangat rendah. Hal ini terlihat dari hasil penelitian bahwa hanya sebesar $17 \%$ responden yang menyatakan berminat terhadap kartu kredit.

Adapun faktor utama yang Memengaruhi minat responden terhadap kepemilikan kartu kredit adalah persepsi kontrol perilaku. Faktor kedua adalah faktor norma subjektif. Lalu faktor ketiga adalah sikap terhadap perilaku.

Persepsi kontrol perilaku dominan Memengaruhi minat kepemilikan kartu kredit. Dalam hal ini, perbankan diharapkan dapat mengedukasi konsumen dengan baik untuk mengubah mindset atau pandangan negatif masyarakat terhadap kartu kredit sehingga kartu kredit dapat diterima secara luas dan digunakan sebagai alat pembayaran non-tunai.

\section{Saran}

Beberapa hal yang dapat dilakukan pada masa yang akan mendatang untuk menjamin kesempurnaan konsep ini, antara lain : penelitian ini hanya mengambil contoh di kota Bogor, diharapkan penelitian berikutnya wilayah yang dijadikan sampel lebih luas sehingga mewakili populasi konsumen pengguna Kartu kredit, pada penelitian ini masih menggunakan teknik pengambilan sampel tak berpeluang (non-probability sampling). Selanjutnya, penelitian selanjutnya agar menambahkan faktor-faktor lain yang belum diteliti pada penelitian ini, seperti persepsi kegunaan (perceived of usefulness), persepsi kemudahan (perceived ease of use). Dengan demikian akan memperkuat konsep untuk penelitian faktor-faktor yang Memengaruhi minat penggunaan kartu kredit.

\section{DAFTAR PUSTAKA}

Abdelrahmamn O. 2011. Consumer search and switching behavior: evidence from the credit card market. [disertasi]. Michigan (US): Wayne State University.

Abdul-Muhmin AG, Umar YA. 2007. Credit card ownership and usage behaviour in Saudi Arabia:
The impact of demographics and attitudes toward debt. Journal of Financial Services Marketing 12(3): 219-234.

Dewi C. 2015. Pengaruh sikap, kepercayaan, persepsi kegunaan, persepsi kemudahaan penggunaan, dan kualitas sistem terhadap minat masyarakat dalam menggunakan kartu kredit (studi kasus pada RSUD “Dr. H. Slamet Martodirdjo" Kabupaten Pamekasan). Jurnal Ilmiah Mahasiswa FEB 3(2): $1-21$

Fathia A. 2012. Faktor determinan minat individu menggunakan kartu kredit: model kombinasi TAM Dan TPB [skripsi]. Malang: Program Sarjana Fakultas Ekonomi dan Bisnis Universitas Brawijaya Universitas Brawijaya.

Fishbein M, Ajzen I. 1991. Belief, Attitude, Intention, and Behavior: An Introduction to Theory and Research. Filipina: Addison-Wesley Publishing Company, Inc.

Gunawan M, Linawati N. 2013. Analisis faktor yang berhubungan dengan pertimbangan cost and benefit kartu kredit. Finesta 1(2): 79-84.

Haryono T. 2013. Model sikap penerimaan masyarakat terhadap pemanfaatan gas alam dalam program pembangunan kota gas: studi kasus Kota Tarakan [disertasi]. Bogor: Manajemen Bisnis Institut Pertanian Bogor.

Hasan J. 2012. Pengembangan model peningkatan minat membeli produk ramah lingkungan: persepektif teori difusi inovasi [tesis]. Bogor: Manajemen Bisnis Institut Pertanian Bogor.

[IBI] Ikatan Bankir Indonesia. 2009. Nasabah kartu kredit BCA paling setia.http://www.ikatanbankir. com/ibi/ [17 April 2014].

Park T, Saplan-Catchapero VJ, Tongjin D. 2012. Predicting knowledge sharing intentions in the public sector: comparing TAM with TPB. International Review of Public Administration 17(2): 93-117.

Ramayah T, Nasurdin A M, Choo LH. 2002. Cardholder's attitude and bank credit card usage in Malaysia. Asian Academy of Management Journal 7(1): 75-102.

Rita MR, Kusumawati R. 2011. Pengaruh variabel sosio demografi dan karakteristik finansial terhadap sikap, norma subyektif dan kontrol perilaku menggunakan kartu kredit (studi pada pegawai di UKSW Salatiga). Jurnal Manajemen dan Keuangan 9(2): 109-128.

Rochmawati. 2013. Pengaruh sikap, norma subjektif, kontrol perilaku persepsian, persepsi risiko, 
persepsi kebermanfaatan terhadap niat penggunaan kartu kredit. Jurnal Ilmiah Mahasiswa FEB 1(2): 1-14.

Safakli OV. 2007. Motivating factors of credit card usage and Ownership: evidence from northern cyprus. Investment Management \& Financial Innovations 4(4):133-143.

Sayono JA. 2009. Analisis faktor-faktor yang memengaruhi kepemilikan, penggunaan, pembayaran, dan peluang terjadinya gagal bayar dalam bisnis kartu kredit. Jurnal Ekonomi dan Bisnis 3(1): 61-80.

Suharjo B, Suwarno. 2002. Model Persamaan Struktural, Teori dan Aplikasinya. Bogor: IPB Press.

Sulistyawaty R. 2012. Perilaku konsumen dalam penggunaan kartu kredit di wilayah DKI Jakarta. [tesis]. Jakarta: Universitas Gunadarma.

Sumarwan U. 2011. Perilaku Konsumen: Teori dan Penerapannya dalam Pemasaran. Jakarta: Ghalia Indonesia.

Wijanto SH. 2008. Structural Equation Modeling dengan Lisrel 8.8. Ed ke-1. Yogyakarta: Graha Ilmu.

Themba G, Tumedi CB. 2012. Credit card ownership and usage behaviour in botswana. International Journal of Business Administration 3(6): 60-71.

Wickramsinghe V, Gurugamage A. 2009. Consumer credit card ownership and usage practices: empirical evidence from Sri Lanka. International Journal of Consumer Studies 33(1): 436-447. 